\title{
32 ways to innovate business models through data: Emerging data-driven solution business model patterns from a study of 471 late stage data-driven startups
}

\author{
Julian Schirmer \\ Montpellier Research in \\ Management \\ Montpellier University \\ France \\ julian.schirmer@etu.umontpellier.fr
}

\author{
René Eber \\ Montpellier Research in \\ Management \\ Montpellier University \\ France \\ $\underline{\text { rene.eber@etu.umontpellier.fr }}$
}

\author{
Isabelle Bourdon \\ Montpellier Research in \\ Management \\ Montpellier University \\ France \\ isabelle.bourdon@umontpellier.fr
}

\begin{abstract}
Solution business model patterns, which describe solutions to recurring business problems, play a central role in business innovation as $90 \%$ of business model innovations are recombinations of solution business model patterns. Research so far has only identified seven data-driven solution business model patterns limited to revenue models in data-driven services. We have systematically analyzed 471 late stage, data-driven startups, identifying 32 data-driven solution business model patterns. We categorized them along the nine business model building blocks from the business model canvas of Osterwalder and Pigneur. A framework that is often used by practitioners in business model innovation projects. This paper significantly expands the research conducted on data-driven solution business model patterns. Furthermore, the identified data-driven solution business model patterns will support practitioners in data-driven business model innovation.
\end{abstract}

\section{Introduction}

We are at the edge of a new wave of data-driven innovation. The world's data is expected to grow from 33 zettabytes in 2018 to 175 zettabytes by 2025 [1]. CIOs and IT Leaders are convinced that data, analytics, and artificial intelligence play a major role in reshaping competition and that they need to innovate their business models for the data age [2].

For such innovation endeavors, collections of solution business model patterns (SBMPs) play a central role, as $90 \%$ of all business model innovations are recombinations of SBMPs [3]. SMBPs describe generic ways to innovate parts of a business model and are leveraged in innovation projects to increase efficiency, spur creativity, and help overcome cognitive barriers in the business model innovation process [4].
However, the current literature on SBMPs is outdated and not adapted to data-driven innovation. Remane et al. [5], who, to our knowledge, conducted the most comprehensive literature review on SBMPs, identified 95 SBMPs in literature. However, they call for further research, as they found no original source of SBMPs created after 2014. They argue that further research is needed to identify new emerging SBMPs from digital trends, such as data-driven SBMPs (DDSBMPs).

So far, only Schüritz et al. [6] have researched DDSBMPs. However, their scope is very limited, as they studied the revenue models of data-driven services from startups and identified 7 DD-SBMPs. Considering that the revenue model only covers a part of the business model, we argue that far more DD-SBMPs can be identified, and further research is needed. We have decided to focus our study on startups, as they provide ample opportunity for uncovering relatively novel phenomena [7] and as they tend to focus on a single business model contrary to traditional businesses [8], facilitating the analysis. Furthermore, we have leveraged the business model canvas from Osterwalder and Pigneur [9] as a structuring framework for our study. Practitioners widely use this framework in business model innovation projects. The business model canvas is a great way to describe a business model and consists of the following building blocks (in the following referred as "blocks": Customer Segments, Customer Relationships, Channels, Value Proposition, Key Activities, Key Resources, Key Partners, Revenue Streams, and Cost Structure.

Therefore, our research question is: What are the emerging DD-SBMPs from startups within the business model canvas from Osterwalder and Pigneur?

Our contribution has two implications. From an academic perspective, we expand the research field of DD-SBMPs, complementing the research from Schüritz et al. and the database of SBMPs from Remane et al. 
From a managerial perspective, the identified DD-SBMPs will support practitioners in data-driven innovation processes and are easy to integrate into current business model innovation practices as they are structured within the business model canvas from Osterwalder and Pigneur.

To close the identified research gap, this paper is structured as follows. First, we outline the theoretical foundation of DD-SBMPs and review the existing literature. Second, we outline the research design. Third, we present the newly identified DD-SBMPs within the business model canvas from Osterwalder and Pigneur and illustrate each through a startup example. Finally, we discuss our findings, research limitations, and provide a conclusion of our work.

\section{Definitions and status of research}

Our research builds upon the two research fields of data-driven business models and solution business model patterns that we define in the following. Furthermore, we present the research that has been undertaken in this field so far.

\subsection{Definition of data-driven business models}

Researchers have pointed out that companies have widely used data, but that a business model qualifies only as "data-driven" once it uses data as its key resource [10]. Hartmann et al. [10] further specify this definition by highlighting three implications:

- "First, a [data-driven business model] is not limited to companies conducting analytics but includes companies that are merely aggregating or collecting data."

- "Second, a company may sell not just data or information but also any other product or service that relies on data as a key resource."

- "Third, it is obvious that any company uses data in some way to conduct business - even a small restaurant relies on its suppliers' contact details. However, the focus is on companies using data as a key resource for their business model."

\subsection{Definition of SBMPs}

As described in the introduction, solution business model patterns (SBMPs) play an important role in the business model innovation process. Unfortunately, researchers often refer to business model patterns without clearly distinguishing between prototypical and solution business model patterns.

Prototypical business model patterns define recurring types of companies within an industry and are described by holistic business models [11]. They permit a quick orientation when entering a new market but are not appropriate for innovating new business models [11]. In contrast, solution business model patterns (SBMPs) are building blocks for designing business models [11]. Thus, SBMPs and not prototypical business model patterns are leveraged for business model innovation [11].

To further illustrate the difference and the application of SBMPs in innovation projects, we outline a fictive example. A company with a long tradition in producing and selling printers with corresponding printer cartridges wants to innovate its business model. To be inspired in the ideation phase, the company first tries to leverage prototypical business model patterns. The company understands that itself qualifies as the prototypical business model pattern "Manufacturer: Create and sell physical assets" [12] and that others in the industry qualify as the prototypical business model pattern "Retailer: Buy and sell physical assets" [12]. However, unless the company decides to sell all its production facilities to become a retailer, these prototypical business model patterns do not help the company innovate its business model. In a second attempt, the company leverages the often cited SBMP "razor/razor-blade" [3]. Companies offer a cheap basic product ("razors") with expensive complements that often need to be replaced ("blades"). The overpriced complements subsidize the basic product. The SBMP has originally been derived from Gillette [3], but many companies apply this SBMP. For example, Nespresso machines are sold cheap, while the Nespresso capsules are comparatively expensive. The company gets inspired and starts offering its printers for cheap while increasing the price for its printer cartridges.

Having outlined the difference between prototypical and SBMPs, a more detailed definition derived from the literature of SBMPs is outlined. SBMPs describe a "solution" to a recurring "problem" that needs to be solved [13]. They describe the core of the solution, which means that a business model pattern often describes a solution for only a certain part of a company's business model [14]. Hence, complete business models of companies are often a combination of several SBMPs [9]. Furthermore, a SBMP should be usable "a million times over" and therefore requires a certain generalization [11].

\subsection{Status of research on data-driven SBMPs}

Data-driven SBMPs (DD-SBMPs) need to comply with both previous definitions. To the best of our knowledge so far, only the paper from Schüritz et al. [6] has identified seven DD-SBMPs (further outlined in the findings chapter), while five papers have already identified 24 data-driven prototypical business model patterns $[10,15,16,17,18]$. However, the work from 
Schüritz et al. [6] has several important limitations regarding our research question. First, they only studied DD-SBMPs emerging from data-driven services, thus, leaving aside DD-SBMPs emerging from data-driven products, which are part of the definition of data-driven business models outlined before. Second, Schüritz et al. state that they studied only the revenue model of startups, which, as they define it, represents only a part of the business model. We aim at a more holistic study of business models from startups to identify DDSBMPs. Finally, the number of seven DD-BMPs identified by them seems quite small compared to the 95 SBMPs identified in the literature by Remane et al. [5]. Therefore, we do believe that further research on DD-SBMPs is needed.

\section{Methodology}

Researchers leverage different research designs for the identification of SBMPs (see [6,11]). However, the research designs can be summarized in the following three phases: data collection, codification of companies, and finally, SBMP identification. In the following three subchapters, we outline how we adapted the research design for our scope.

\subsection{Phase 1: Data collection}

We leveraged the PRISMA approach for systematic identification of and data collection on companies [19], illustrated in Figure 1.

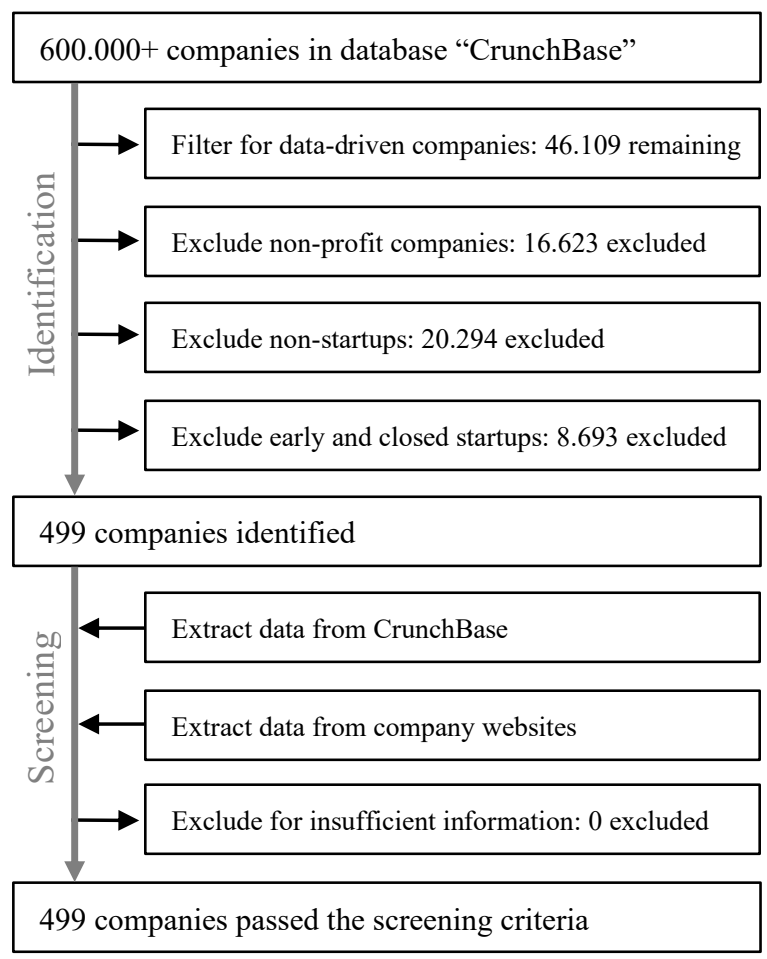

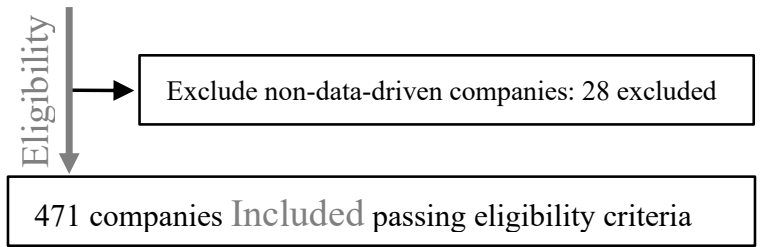

Figure 1: Data collection process

The application of the four PRISMA steps is described in the following.

Identification: For their research, Schüritz et al. [6] have leveraged the startup database AngelList to identify suitable startups systematically. However, we opted for the startup database CrunchBase as it is the world's most comprehensive database for high technology startups [20] and is thus better suited to find data-driven business models. CrunchBase was founded in 2007 and contains more than 600 thousand company profiles with over 55 million yearly users (crunchbase.com). Many researchers have used this database (e.g., [5, 20]. To select the companies, we performed the company search on the $24^{\text {th }}$ of November 2019. We used several filter options for CrunchBase. First, to focus only on datadriven companies, we reviewed all category group filters and selected "data \& analytics" OR "artificial intelligence" resulting in 46.109 companies. Second, as our research focuses on business model innovation for corporations, we have excluded non-profit organizations by filtering the company type "for-profit" excluding 16.623 companies. Third, to focus only on startups, we have excluded from the filter funding status "M\&A" (Merger \& Acquisition), "Private Equity" and "IPO" (Initial Public Offering), excluding 20.294 companies. Further, Hartmann et al. [10] stress that early-stage startups first need to prove their business model's success and are prone to fail early before reaching the late-stage startup phase. Thus, to reduce the risk to study startups with immature business models, we have decided to filter for startups who successfully passed the early startup phase by filtering for funding status, excluding "seed" and "early-stage venture", as well for operating status "active" excluding 8.693 companies. Thus, we identified a manageable number of 499 companies.

Screening: Through CrunchBase, we extracted the following data in an excel: Name, full description, short description, categories, website address. Furthermore, we extracted relevant information for the description of the business models from the companies' websites and integrated it in the excel. While in other similar researches, we had to exclude companies for insufficient provided information, these data-driven startups were all well described. 
Eligibility: We excluded 28 startups as they did not qualify as data-driven, as defined on page 2 .

Included: We included 471 data-driven startups in our study.

\subsection{Phase 2: Codification of companies}

In the second phase, the startups are assessed and coded for pattern identification. Figure 2 illustrates the codification process.

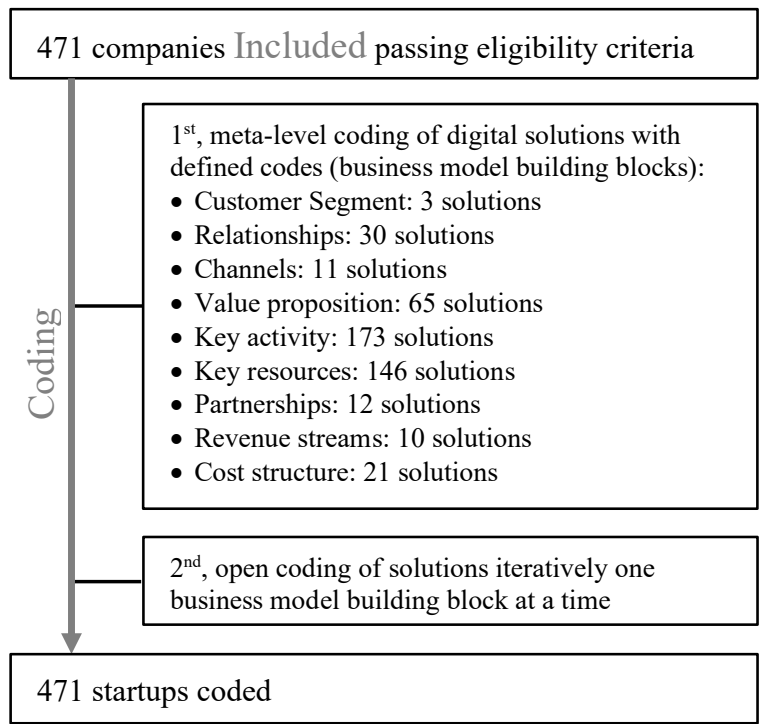

\section{Figure 2: Codification of companies}

Given the large set of 471 companies, we applied a similar approach as Remane et al. [21]. They coded 487 companies in two steps. First, they applied a meta-level coding to cluster the companies. Second, they analyzed each cluster separately for more efficient pattern identification.

For the first step of meta-level codification, Amshoff et al. [11] stress the importance of an overall framework to cluster the SBMPs along with affected business model building blocks. For our research, we choose the business model framework from Osterwalder and Pigneur [9], as it is widely used in business model innovation research (cited by $>10 \mathrm{k}$ articles on Google Scholar on the 25th of November 2019). Therefore, the blocks' codes are as follows [9]: Customer Segment, Value Propositions, Channels, Customer Relationships, Revenue streams, Key Resources, Key Activities, Key Partnerships, and Cost Structure.

For the second coding within each affected block, a more granular coding is needed. Amshoff et al. [11] derived 43 business model variables and corresponding configuration options along the BMBBs from websites, industry reports, literature, trade fair surveys, and expert interviews. However, their focus on condition monitoring SBMPs is more specific than our focus on
DDSBMPs for which no predefined codes could be derived beforehand. Therefore, we adapted the hybrid coding approach from Schüritz et al. [6]. On the one hand, some research has already focused on data-driven business models, and this research can be leveraged as the underlying basis of a research inquiry. In this case, Saldaña [22] recommends using provisional lists of codes derived from existing literature. On the other hand, as the field of DD-SBMPs has not been explored beforehand, "open coding" should be used for theory development [23]. We thus decided to complement the list of provisional codes through open coding. As provisional codes, we leveraged the taxonomy on datadriven business models by Hartmann et al. [10], as the taxonomy specifies features of data-driven startups for the key blocks. As the act of coding is subject to the individual coder [24], we minimized this bias by performing all coding steps through two researchers independently. The codes were then reviewed, disputes were solved through mutual discussion sessions, and when needed, a third reviewer was involved in solving the dispute.

\subsection{Phase 3: Pattern identification}

In the third phase, the DDSBMPs are identified based on the codification of the startups. The objective was to converge the startups to DDSBMPs at an abstraction level similar to the SBMPs identified in the literature by Remane et al. [5]. Figure 3 summarizes the process.

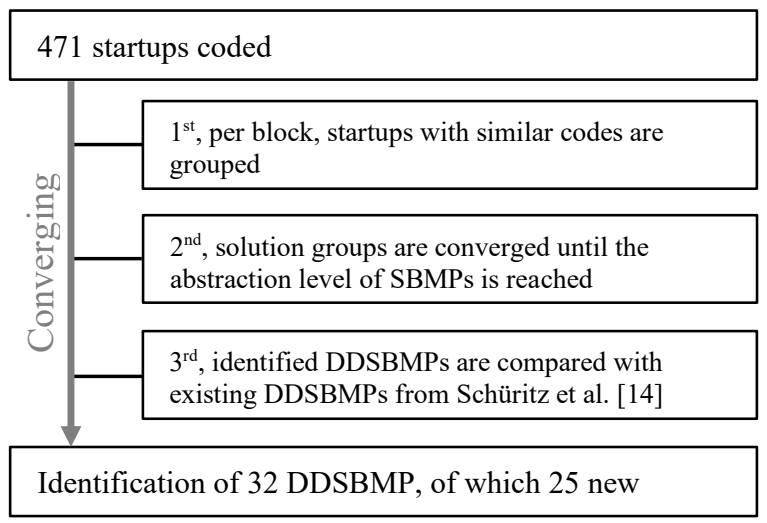

Figure 3: DDSBMP identification

The business model "blocks" from Osterwalder and Pigneur [9] proved very useful, as each startup could clearly be allocated to one bloc. This allowed reducing the complexity of analyzing the 471 startups, as the researchers could focus on one block at a time. Within each block, startups with identical or very similar value propositions were grouped in a first step. Next, those groups with similar solution logics were clustered into DDSBMPs through several iterations and alignments between the researchers. Finally, we made sure to build 
upon the existing literature by looking for overlaps of the identified DDSBMPs with the ones identified by Schüritz et al. [6], as described in table 2 .

\section{Findings}

\begin{tabular}{|c|c|c|c|c|c|}
\hline Key Partners & Key Activities & \multicolumn{2}{|c|}{ Value Propositions } & Customer Relationships & Customer Segments \\
\hline \multirow[t]{3}{*}{$\begin{array}{l}\text { - Data Coopetition } \\
\text { - Partner Dating } \\
\text { - Gain Sharing }\end{array}$} & 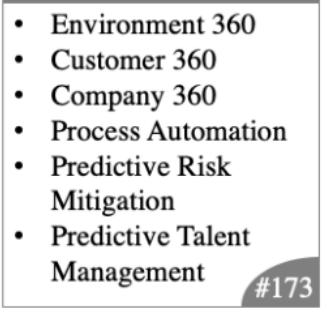 & \multirow{3}{*}{\multicolumn{2}{|c|}{$\begin{array}{l}\text { - Materializing Digital } \\
\text { - Products } \\
\text { Physical-Digital } \\
\text { - } \text { Pybrid } \\
\text { - } \text { Ofoduct Servitization } \\
\text { - } \text { DIY Enablement } \\
\text { - Offering } \\
\text { - Democratization } \\
\text { - Instant Offering } \\
\text { AI Enhanced } \\
\text { - Physical Products } \\
\text { - } \text { Dnsight as Offering } \\
\text { Offering }\end{array}$}} & $\begin{array}{ll}\text { - } & \text { Adaptive Identity } \\
\text { - } & \text { Tailored Stories } \\
\text { - } & \text { Proactive Messaging }\end{array}$ & \multirow[t]{3}{*}{ - Serving the Unserved } \\
\hline & Key Resources & & & Channels & \\
\hline & 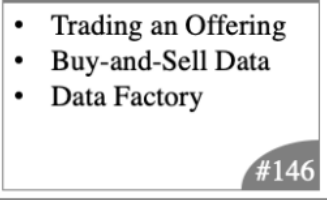 & & & $\begin{array}{ll}\text { - } & \text { Channel } \\
& \text { Orchestration }\end{array}$ & \\
\hline \multicolumn{3}{|l|}{ Cost Structure } & \multicolumn{3}{|c|}{ Revenue Streams } \\
\hline \multicolumn{2}{|l|}{ - Plug and Play } & & \multicolumn{2}{|c|}{$\begin{array}{l}\text { - Usage Fee } \\
\text { - Pay with Data }\end{array}$} & $\begin{array}{l}\text { re-Ads } \\
\text { ription }\end{array}$ \\
\hline
\end{tabular}

Legend: 13 number of startups per business model "block"

\section{Figure 4: Overview of the identified DD-SBMPs in the business model canvas from Osterwalder and Pigneur [9]}

Figure 4 provides an overview of the identified DD-SBMPs. From the 471 startups, a total of 32 DD-SBMPs have been identified, of which 7 have already been described by Schüritz et al. [6]. Figure 4 also states how many startups have been allocated to which business model block within the business model canvas.

Table 1 and Table 2 on the following pages provide further details for each of the DD-SBMPs and are structured as follows.

The first column defines the DD-SBMPs. The respective name is written in bold. The following definition is aligned with the style of the SBMPs in the literature reviewed by Remane et al. [5], which facilitates the integration of the DD-SBMPs in the research body. Those from Schüritz et al. are clearly marked with a "[6]".

The second column provides for each DD-SBMPs a startup example for illustration. These examples help the reader to better understand the DD-SBMPs by seeing them in concrete cases. For the DD-SBMPs from Schüritz et al., their examples are leveraged to ensure that the initial meaning is reproduced correctly.
The third column states the number of startups that have been identified from the 471 startups that apply the specific DD-SBMP, providing additional insight into the frequency of each DD-SBMP.

The overview from Figure 4 and the details from Table 1 and Table 2 can be leveraged in several ways.

First, practitioners can leverage the findings in business innovation workshops. On the one hand, practitioners aiming to innovate a specific block of their business model can focus on the respective DD-SBMPs are mapped in the overview in Figure 4. On the other hand, practitioners seeking inspiration can randomly browse through the DD-SBMPs to better understand the different levers for data-driven innovation and brainstorm how specific DD-SBMPs could be applied to their company.

Second, academics can study data innovation potential from different points of view. The number of startups per block or at a more granular level per DD-SBMP provides insight into the focus of current startups. The repartition of the number of DD-SBMPs per block provides information on various data-driven innovations within the business model canvas. 


\begin{tabular}{|c|c|c|}
\hline DD-SBMP & Startup example & $\#$ \\
\hline $\begin{array}{l}\text { Serving the Unserved: Using data-driven insights, companies } \\
\text { can expand their offering to previously untargeted customers, } \\
\text { thus increasing the number of potential customers. }\end{array}$ & $\begin{array}{l}\text { "Deserve", a banking company that uses various data } \\
\text { sources to build a smart credit score giving loans to } \\
\text { people that traditionally do not qualify for a credit } \\
\text { because of the lack of credit history. }\end{array}$ & 3 \\
\hline $\begin{array}{l}\text { Adaptive Identity: Understanding which customer would } \\
\text { prefer which company identity is based on analytics and } \\
\text { adapting the company's perception at each touchpoint for each } \\
\text { customer to increase brand loyalty. }\end{array}$ & $\begin{array}{l}\text { "Afiniti", a tech company, leverages an AI to instantly } \\
\text { match the call agents that best fit individual customers on } \\
\text { a personalized level. }\end{array}$ & 8 \\
\hline $\begin{array}{l}\text { Tailored Stories: Tailoring the sales story to each customer } \\
\text { individually to achieve highly relevant offerings for } \\
\text { heterogeneous customers. }\end{array}$ & \begin{tabular}{|l|} 
"Qubit", a tech company, personalizes product \\
descriptions and recommendations to customers based on \\
analytics-driven segmentation.
\end{tabular} & 15 \\
\hline $\begin{array}{l}\text { Proactive Messaging: Communicating messages to the } \\
\text { customers proactively to provide the right information at the } \\
\text { right time at the right place to stay engaged with customers. }\end{array}$ & $\begin{array}{l}\text { "Yieldbot", a tech company, predicts the intent of } \\
\text { customers to reach out to them at the moment of greatest } \\
\text { potential influence on their buying decisions. }\end{array}$ & 7 \\
\hline $\begin{array}{l}\text { Channel Orchestration: Providing the customer with a } \\
\text { seamless experience across channels through a cohesive, } \\
\text { omnichannel view of the customer and unified multi-channel } \\
\text { content management. }\end{array}$ & $\begin{array}{l}\text { "Signal", a tech company, collects and matches identifiers } \\
\text { across devices and touchpoints to identify customers } \\
\text { regardless of the channel. }\end{array}$ & 11 \\
\hline $\begin{array}{l}\text { Materializing Digital Products: Creating physical products } \\
\text { based on a digital variant by using, e.g., 3D printing by } \\
\text { transporting advantages of the digital to the physical world, } \\
\text { such as eliminating intermediaries and reducing overheads... }\end{array}$ & $\begin{array}{l}\text { "Key Me", a locksmith company, leverages 3D printing } \\
\text { to offer the ability to duplicate the customer's keys in } \\
\text { smart kiosks through from previously obtained digital } \\
\text { shape to physical products. }\end{array}$ & 2 \\
\hline $\begin{array}{l}\text { Physical - Digital Hybrids: Blending the physical and digital } \\
\text { world enables companies to transport the customer's interaction } \\
\text { experience to the individual context of customers using } \\
\text { augmentation. }\end{array}$ & $\begin{array}{l}\text { "Hiscene", a technology company, uses augmented } \\
\text { reality to bring a new shopping experience allowing } \\
\text { customers to try luxurious watches such as Rolex, } \\
\text { Omega, and IWC on their wrist. }\end{array}$ & 2 \\
\hline $\begin{array}{l}\text { Product Servitization: Augmenting products through } \\
\text { additional data-driven services to help customers gain more } \\
\text { value from the offering. }\end{array}$ & $\begin{array}{l}\text { "Tonal", a fitness machine manufacturer, sells fitness } \\
\text { equipment, which provides personalized and adaptive } \\
\text { fitness coaching during use. }\end{array}$ & 5 \\
\hline $\begin{array}{l}\text { Offering Integration: Integrating other companies' offerings } \\
\text { based on data insights to solve the customers' requirements } \\
\text { holistically to improve customer experience. }\end{array}$ & $\begin{array}{l}\text { "Fundbox", a credit network, analyses transaction data in } \\
\text { real-time and offers credit plans that companies can pass } \\
\text { on to their customers to improve close rates. }\end{array}$ & 11 \\
\hline $\begin{array}{l}\text { DIY Enablement: Enabling customers to do data-driven value } \\
\text { creation steps themselves as an alternative to buying products } \\
\text { from companies. }\end{array}$ & $\begin{array}{l}\text { "3D Hubs", an online platform, allows non-experts to } \\
\text { easily design 3D models and use publicly accessible 3D } \\
\text { printing factories. }\end{array}$ & 10 \\
\hline $\begin{array}{l}\text { Offering Democratization: Reducing barriers such as cost, } \\
\text { time, knowledge to offerings based on data-driven solutions to } \\
\text { make them available to everyone. }\end{array}$ & $\begin{array}{l}\text { "Color", a health care company, applic } \\
\text { to genetic testing to provide every cus } \\
\text { genetic information for a fraction of tr }\end{array}$ & 6 \\
\hline $\begin{array}{l}\text { Instant Offering: Speeding up the process through data-driven } \\
\text { automation for the customer to value delivery to offer a better } \\
\text { customer experience. }\end{array}$ & $\begin{array}{l}\text { "Lemonade", an insurance company, replaces brokers and } \\
\text { bureaucracy with bots and machine learning to offer zero } \\
\text { paperwork and instant everything for home insurances. }\end{array}$ & 3 \\
\hline $\begin{array}{l}\text { AI-enhanced Physical Products: Enhancing the physical } \\
\text { offering with smart capabilities allows companies to better } \\
\text { tackle the customers' "job to get done." }\end{array}$ & $\begin{array}{l}\text { "Almotive", a solution provider for self-driving } \\
\text { technology, uses cameras on cars to mimic the visual } \\
\text { capabilities of a human to enable autonomous driving. }\end{array}$ & 4 \\
\hline $\begin{array}{l}\text { Insight as Offering: Deriving insights from data that have a } \\
\text { value for others. This can range from tailor-made insights for } \\
\text { an individual customer/client as "cancer recognition" to general } \\
\text { insights as "weather prediction." }\end{array}$ & $\begin{array}{l}\text { "Resson", a bioinformatics company, uses cloud-based } \\
\text { data processing, swarm robotics, and data analytics to } \\
\text { give farmers insights about crop status and health, } \\
\text { providing operators with the information required to } \\
\text { optimize agricultural operations and profitability. }\end{array}$ & 17 \\
\hline $\begin{array}{l}\text { Data-tailored-offering [6]: Tailoring better the offer to } \\
\text { customers' specific needs by getting private data from } \\
\text { customers upfront and providing additional data on suitable } \\
\text { providers. }\end{array}$ & \begin{tabular}{|l|} 
"SchoolSparrow", a real-estate searching platform, \\
proposes to its clients housings based on their private data \\
performance measures of close by public schools $[6]$.
\end{tabular} & 5 \\
\hline $\begin{array}{l}\text { Environment } \mathbf{3 6 0}^{\circ} \text { : Monitoring the business environment to } \\
\text { react to competitor strategies, identify market opportunities, } \\
\text { track market dynamics, and alert timely about events (e.g., } \\
\text { earthquakes). }\end{array}$ & $\begin{array}{l}\text { "Signal AI", a business intelligence company, uses } \\
\text { natural language processing to analyze media and } \\
\text { regulatory data to warn companies of relevant regulatory } \\
\text { changes. }\end{array}$ & 14 \\
\hline
\end{tabular}

Table 1: Identified DD-SBMPs (1/2) 


\begin{tabular}{|c|c|c|}
\hline DD-SBMP & Startup example & $\#$ \\
\hline $\begin{array}{l}\text { Customer } \mathbf{3 6 0}^{\circ} \text { : Tracking customer behavior and creating } \\
\text { customer insights as a foundation for more customer-centric } \\
\text { offerings, effective marketing, and high customer engagement. }\end{array}$ & $\begin{array}{l}\text { "Glassbox", a provider of instant customer experience } \\
\text { replay, leverages behavioral analytics to track what } \\
\text { customers are doing and why. }\end{array}$ & 53 \\
\hline $\begin{array}{l}\text { Company } \mathbf{3 6 0}^{\circ} \text { : Gaining transparency about company } \\
\text { processes and measuring performance to enhance the veracity } \\
\text { of KPIs, identify optimization opportunities, and support } \\
\text { management decisions. }\end{array}$ & $\begin{array}{l}\text { "Trax", a retail startup, using cameras and AI to track } \\
\text { what is happening on shelves such as out of stock } \\
\text { products or promotion-al compliance. }\end{array}$ & 22 \\
\hline $\begin{array}{l}\text { Process Automation: Automating repetitive tasks using } \\
\text { software, artificial intelligence, or robotics ensures consistent } \\
\text { outcomes while also speeding up the process often at a fraction } \\
\text { of the costs. }\end{array}$ & $\begin{array}{l}\text { "Meero", a photo editing service company, cuts the time } \\
\text { needed for post-production from } 4 \text { hours to } 60 \text { minutes } \\
\text { drastically by automating this process using artificial } \\
\text { intelligence. }\end{array}$ & 22 \\
\hline $\begin{array}{l}\text { Predictive Risk Mitigation: Mitigating risk using data-driven } \\
\text { pattern recognition to prevent malicious activities such as } \\
\text { cyber-attacks before happening or act quickly if detected. }\end{array}$ & $\begin{array}{l}\text { "Exabeam", a big data security analytics company, uses } \\
\text { behavior intelligence technology to fundamentally } \\
\text { change the way cyberattacks are detected by focusing on } \\
\text { attacker behavior rather than ever-changing malware and } \\
\text { tools. }\end{array}$ & 42 \\
\hline $\begin{array}{l}\text { Predictive Talent Management: Predictive talent } \\
\text { management helps acquire, train, and retain a diverse talent } \\
\text { pool by predicting the needs and motives for talents } \\
\text { individually for more targeted and tailored measures. }\end{array}$ & $\begin{array}{l}\text { "Eightfold" is a talent platform that uses machine } \\
\text { learning to predict the next role for potential candidates } \\
\text { combining enterprise outcome data and public data. }\end{array}$ & 20 \\
\hline $\begin{array}{l}\text { Trading an Offering: Building a proprietary dataset, which } \\
\text { can lead to a competitive advantage, companies are offering to } \\
\text { build, e.g., infrastructure that will give them access to data } \\
\text { gathering. }\end{array}$ & $\begin{array}{l}\text { "StreetLight Data", a smart mobility company, builds and } \\
\text { provides public infrastructure such as streetlamps to } \\
\text { collect mobility data through sensors installed on the } \\
\text { streetlamps. }\end{array}$ & 2 \\
\hline $\begin{array}{l}\text { Buy-and-sell-data [6]: Acting as a broker for data, buying } \\
\text { potentially interesting data, and selling it to interested parties. }\end{array}$ & $\begin{array}{l}\text { "Zeotap", a data broker company, buys customer data } \\
\text { from telecom operators to sell it to prospective advertisers } \\
\text { who are interested in better tailoring ads [6]. }\end{array}$ & 38 \\
\hline $\begin{array}{l}\text { Data Factory: Building up the tools and infrastructure } \\
\text { necessary to enable the business to put the data sourced to } \\
\text { create value in the form of insights. }\end{array}$ & $\begin{array}{l}\text { "Databricks", a data analytics service company, offers a } \\
\text { unified analytics platform for data science teams to } \\
\text { collaborate with lines of business to speed up the process } \\
\text { by automating analytic workflows. }\end{array}$ & 106 \\
\hline $\begin{array}{l}\text { Data Coopetition: Forming a network for data sharing among } \\
\text { competitors can help companies derive unbiased and } \\
\text { unprecedented insights leading to a competitive advantage } \\
\text { towards non-members. }\end{array}$ & $\begin{array}{l}\text { "Farmers Business Network", a farmer-to-farmer } \\
\text { agronomic information network, improves farmers' } \\
\text { insights by making data useful and accessible, which } \\
\text { increases their product performance, benchmarking... }\end{array}$ & 3 \\
\hline $\begin{array}{l}\text { Partner Dating: Making information about potential partners } \\
\text { available and optionally supporting in identifying the best } \\
\text { match partners. }\end{array}$ & $\begin{array}{l}\text { "Globality", a provider matching platform, leverages an } \\
\text { SME database and machine learning for a dynamic Q\&A } \\
\text { to support project teams identify suppliers for projects. }\end{array}$ & 6 \\
\hline $\begin{array}{l}\text { Gain sharing [6]: Tracking the service's success through data } \\
\text { and paying a success-based fee. }\end{array}$ & $\begin{array}{l}\text { "Predictry", a recommender solution provider, uses } \\
\text { sentiment and behavior analysis for personal } \\
\text { recommendations for shoppers, getting 3-6\% from shops } \\
\text { when a recommendation is converted into sales [6]. }\end{array}$ & 3 \\
\hline $\begin{array}{l}\text { Usage fee [6]: Letting customers pay based on their usage } \\
\text { pattern of the used product/service that is tracked through data. }\end{array}$ & $\begin{array}{l}\text { "VoiceBase", an AI-powered speech analysis provider for } \\
\text { call centers, charges call centers for each analyzed minute } \\
{[6] .}\end{array}$ & 2 \\
\hline $\begin{array}{l}\text { Pay with data [6]: Offering products or services and letting } \\
\text { customers pay with data instead of money. }\end{array}$ & $\begin{array}{l}\text { "GameAnalytics", an analytics company for video games, } \\
\text { offers free analytic services in exchange for access to data } \\
\text { on players that is leveraged for selling reports [6]. }\end{array}$ & 3 \\
\hline $\begin{array}{l}\text { Subscription [6]: Offering different subscription models for } \\
\text { which customers can select the required functionalities and/or } \\
\text { volumes of data services. }\end{array}$ & \begin{tabular}{|l|} 
"AmigoCloud", a mapping technology company, allows \\
its clients to opt into different subscriptions based on data \\
volumes and functionalities for mapping tasks [6].
\end{tabular} & 3 \\
\hline $\begin{array}{l}\text { Endure-ads [6]: Offering products or services and letting } \\
\text { customers not pay with money or data but agreeing to view an } \\
\text { advertisement. }\end{array}$ & $\begin{array}{l}\text { "SambaTV", an entertainment company, offers additional } \\
\text { content on TV shows for free while charging advertisers } \\
\text { for tailored ads to their viewers [6]. }\end{array}$ & 2 \\
\hline $\begin{array}{l}\text { Plug and Play: Reducing investments by leveraging ready to } \\
\text { integrate AI solutions for which little expertise is needed } \\
\text { instead of building them inhouse. }\end{array}$ & $\begin{array}{l}\text { "H2O.ai", an open-source machine learning platform, lets } \\
\text { companies integrate fully functional machine learning } \\
\text { functionalities into their applications, such as fraud } \\
\text { detection or credit risk scoring. }\end{array}$ & 21 \\
\hline
\end{tabular}

Table 2: Identified DD-SBMPs (2/2) 


\section{Discussion}

Overall the startups were well distributed among the business model "blocks", showing the richness of different solutions emerging from data-driven startups.

However, a few trends emerge from the repartition of startups. Most data-driven startups focused on the block "Key Activities" and "Key Resources". "Leveraging data as key resource" being the criteria for startup selection, it seems not surprising that most startups focus on helping companies building up data as a key resource and leveraging this data in their key activities. Even if the majority of startups focused on these two blocks, the block "Value Proposition" has shown the greatest variety with 10 DD-SBMPs compared to 6 DDBMPs for "Key Activities" and only 3 DDBMPs for "Key Resources". Therefore, from a business model innovation perspective, the block "Value Proposition" seems the most interesting to inspire innovation.

To further put these findings into context, we compared them with the SBMPs from Gassmann et al. [3], which is perceived as the most comprehensive collection of SBMPs besides literature reviews [5]. We derive the first observation from the SBMP "Leverage customer data" from Gassmann et al. The SBMP specifies that customer data represents a profitable resource when the appropriate tools are leveraged to aid decision making. This comprehensive description compared to our DD-SBMP findings confirms the call of research from Remane et al. that further research identifying new SBMPs evolving from advances in digital trends (such as DD-SBMPs) was needed. A second observation is that some SBMPs of Gassmann et al. follow a similar logic as some of our DD-SBMP. For example, Gassmann et al. 's SBMP "Hidden revenue" describes a solution in which a company's main offering is proposed for a low-price to the customer, while a third party pays for advertising the customer base, which subsidies the main offering. In similar logic, our DDSBMP "Trading an offering for data" describes a solution in which a company's main offering is proposed for a low-price to the customer while the company receives the collect and monetizes on data, which subsidizes the main offering. A third observation is that some SBMPs of Gassmann et al. can be expanded through

our DD-SBMPs. For example, Gassmann et al. 's SBMP "Digitizing physical products" describes the solution of transforming an existing product or service into a digital variant. Our DD-SBMP "Materializing digital products" describes the solution of transforming a digital variant of a physical product back into a physical product (e.g., through 3D printing).

\section{Conclusion}

SBMPs play a major role in efficient data-driven business model innovation as $90 \%$ of all business model innovations are a recombination of existing business model patterns. Research so far had only identified seven DD-SBMPs.

In this article, we identified 32 DD-SBMPs, of which 7 were already identified by Schüritz et al. [6] and mapped them onto the business model canvas from Osterwalder and Pigneur [9]. The contribution of our article is twofold.

From an academic perspective, we were able to expand the research field on DD-SBMPs and outline future opportunities further to increase the maturity of this emerging field of research. Such endeavors of expanding the knowledge on data-driven business model innovation help researchers understand how technology advances can be linked with the creation of economic value [25].

From a managerial perspective, the collection of identified DD-SBMPs can significantly support managers to be more efficient in innovating their business models [11, 13], as it can help practitioners by addressing efficiency, spur creativity and help overcome cognitive barriers in the business model innovation process [4]. Clearly linking the identified DD-SBMPs to real examples and the business model "blocks" is perceived as the most beneficial approach in supporting business model innovation endeavors [26]. Hopefully, this helps managers counteract the cognitive bias of sticking to business model configurations that are already known [27].

Our study is not free of limitations. First, our research focuses on data-driven startups identified on CrunchBase. This implies several limitations. Studying startups has the advantage of being able to uncover relatively novel phenomenons [7] and to study companies with more distinguishable SBMPs than traditional businesses [8]. However, startups do not necessarily cover all SBMPs. For example, Amshoff et al. [11] identify the SBMP "condition monitoring systems for own machines and plants" which is far more likely to appear in a traditional company context. Also, even though CrunchBase is the world's most comprehensive database for high technology startups [20], the list of startups is certainly not exhaustive (e.g., CrunchBase does not include Africa as a region filter). As the companies pick the tags we used to identify datadriven startups, we cannot guarantee to have identified all data-driven startups on CrunchBase.

Therefore, future research needs to be conducted to identify DD-SBMPs based on different objects of study.

Second, we mainly leveraged the description of startups on CrunchBase and information provided on the startups' websites to identify DD-SBMPs. 
Third, the identified DD-SBMPs are limited regarding their applicability in practice, as the page limitation of this article did not allow for an extensive explanation of all DD-SBMPs and their examples.

More extensive explanations of the identified DDSBMPs is needed, as SBMPs need to be understood thoroughly before they can be leveraged by managers for strategic endeavors such as business model innovation [28]. Gassmann et al. [3] provide an example of how to augment the applicability in practice of identified BMPs. Their book "The business model navigator" describes 55 business model patterns on 400 pages, outlining each business model pattern with several examples and providing guidance on how to leverage the business model patterns in a business model innovation project.

Thus, further work is needed to make the identified DD-SBMPs available in the right form to managers.

\section{References}

[1] D. Rydning, J. Reinsel, J. Gantz, "The digitization of the world from edge to core.", International Data Corporation, Framingham, 2018.

[2] J. Garfinkel, "Gartner Survey of More Than 3,000 Cios Reveals That Enterprises Are Entering the Third Era of IT" Gartner, Orlando, 2018.

[3] O. Gassmann, K. Frankenberger, and M. Csik, The business model navigator: 55 models that will revolutionise your business, Pearson, London, 2014.

[4] H. Chesbrough, "Business model innovation: opportunities and barriers.", Long range planning 43 (2), 2010, pp. 354-363.

[5] G. Remane, J. A. Hanelt, J. F. Tesch, and L. M. Kolbe, "The business model pattern database- a tool for systematic business model innovation.", International Journal of Innovation Management 21 (01), 2017, pp. 1-61.

[6] R. Schüritz, S. Seebacher, and R. Domer, "Capturing Value form Data: Revenue Models for Data-Driven Services.", Proceedings of the 50th Hawaii, 2017.

[7] P. Criscuolo, N. Nicolaou, and A. Salter, "The elixir (or burden) of youth? Exploring differences in innovation between startups and established firms.", Research Policy 41 (2), 2012, pp. 319-333.

[8] V. Sabatier, V. Mangematin, and T. Rousselle, "From recipe to dinner: business model portfolios in the European biopharmaceutical industry.", Long Range Planning 43 (2), 2010, pp. 431-447.

[9] A. Osterwalder, and Y. Pigneur, Business model generation: a handbook for visionaries, game changers, and challengers, John Wiley \& Sons, Hoboken, 2010.
[10] P. M. Hartmann, M. Zaki, N. Feldmann, and A. Neely, "Capturing value from big data-a taxonomy of data-driven business models used by startup firms." International Journal of Operations \& Production Management 36 (10), 2016, pp. 13821406.

[11] B. Amshoff, C. Dülme, J. Echterfeld, and J. Gausemeier, „Business model patterns for disruptive technologies." International Journal of Innovation Management 19 (03), 2015, pp. 1-22.

[12] P. Weill, T. W. Malone, V. T. D'Urso, G. Herman and S. Woerner, "Do some business models perform better than others? A study of the 1000 largest US firms.", MIT Center for coordination science working paper, 2005, pp. 226.

[13] A.B. Abdelkafi, N. S. Makhotin, and T. Posselt, "Business model innovations for electric mobilitywhat can be learned from existing business model patterns?", International Journal of Innovation Management 17 (01), 2013, pp. 1-41.

[14] P. Weill, and M. Vitale, Place to space: Migrating to eBusiness Models, Harvard Business Press, Boston USA, 2001

[15] R. Schroeder, "Big data business models: Challenges and opportunities.", Cogent Social Sciences 2 (1), 2016, pp. 1-15.

[16] A. Rizk, B. Bergvall-Kåreborn, and A. Elragal, "Towards a Taxonomy for Data-Driven Digital Services.", Proceedings of the 51st Hawaii International Conference on System Sciences, Hawaii USA, 2018

[17] D. Hodapp, G. Remane, A. Hanelt, and L. M. Kolbe, "Business Models for Internet of Things Platforms: Empirical Development of a Taxonomy and Archetypes.", Proceedings of the 14th International Conference on Wirtschaftsinformatik, Siegen Germany, 2019

[18] G. M. Schmidt, and C. T. Druehl, "When is a disruptive innovation disruptive?", Journal of product innovation management 25 (4), 2018, pp. 347-369.

[19] A. Liberati, D. G. Altman, J. Tetzlaff, C. Mulrow, P. C. Gøtzsche, J. P. Ioannidis, and D. Moher, "The PRISMA statement for reporting systematic reviews and metaanalyses of studies that evaluate health care interventions: explanation and elaboration", Journal of clinical epidemiology, 62(10), 2009, e1-e34.

[20] A. Marra, P. Antonelli, L. Dell'Anna, and C. Pozzi, "A network analysis using metadata to investigate innovation in clean-tech-Implications for energy policy.”, Energy Policy 86 (1), 2015, pp. 17-26.

[21] G. Remane, B. Hildebrandt, A. Hanelt and L. M. Kolbe, "Discovering New Digital Business Model Types-a Study of Technology Startups from the Mobility Sector.", Proceedings of the 20th Pacific Asia Conference on Information Systems, Chiayi Taiwan, 2016. 
[22] J. Saldaña, The coding manual for qualitative researchers, Sage, London, 2009.

[23] J. M. Corbin, and A. Strauss, "Grounded theory research: Procedures, canons, and evaluative criteria." Qualitative sociology 13 (1), 1990, pp. 321.

[24] K. Charmaz, Constructing grounded theory: A practical guide through qualitative analysis, Sage, London, 2006.

[25] M. M. Al-Debei, and D. Avison, "Developing a unified framework of the business model concept.", European Journal of Information Systems 19 (3), 2010, pp. 359-376.

[26] A. Osterwalder, Y. Pigneur, and C. L. Tucci, "Clarifying business models: Origins, present, and future of the concept.", Communications of the association for Information Systems 16 (1), 2005, pp. 1.

[27] R. Bohnsack, J. Pinkse, and A. Kolk, "Business models for sustainable technologies: Exploring business model evolution in the case of electric vehicles.", Research Policy 43 (2), 2014, pp. 284300.

[28] G. Gavetti, and J. W. Rivkin, "How strategists really think." Harvard Business Review 83 (4), 2005, pp. 54-63. 